\title{
Identifikasi Tema Wisata Budaya dan Sejarah di Kota Surabaya (Studi Kasus: Sepanjang Sungai Kalimas)
}

\author{
Felicia Esterlita Nugroho dan Hertiari Idajati \\ Departemen Perencanaan Wilayah dan Kota, Fakultas Arsitektur, Desain dan Perencanaan, \\ Institut Teknologi Sepuluh Nopember \\ e-mail: hertiari.idajati@urplan.its.ac.id
}

\begin{abstract}
Abstrak - Surabaya memiliki daya tarik potensi wisata dan keunikan budaya dan sejarah sehingga menarik wisatawan domestik dan internasional. Pariwisata menjadi salah satu fokus pembangunan karena meningkatnya jumlah kunjungan wisatawan ke Surabaya. Pertumbuhan tersebut karena adanya daya tarik potensi wisata dan keunikan budaya dan sejarah di Kota Surabaya, terutama di sepanjang Sungai Kalimas sehingga dapat menarik wisatawan domestik dan internasional. Namun, objek daya tarik budaya dan sejarah di Surabaya sepi peminat, ditunjukkan dengan tidak meratanya kunjungan di setiap DTW. Penelitian ini bertujuan untuk mengidentifikasi tema wisata khusus budaya dan sejarah sehingga wisatawan dapat dengan mudah menentukan objek yang akan dikunjungi sesuai minat masing-masing di Kota Surabaya. Metode yang digunakan dalam artikel ini adalah identifikasi melalui analisis deskriptif yang berasal dari stakeholder kunci ditambahkan dengan hasil observasi di lapangan. Hasil analisis teridentifikasi bahwa terdapat tema 5 kelompok jalur wisata budaya dan sejarah di Surabaya. Tema sejarah maritim, tema perjuangan kemerdekaan, tema budaya Arab dan Pecinan, dan tema permukiman kolonial serta bangunan kolonial.
\end{abstract}

Kata Kunci-tema, jalur wisata, budaya dan sejarah, Surabaya

\section{PENDAHULUAN}

$\mathrm{P}$ ARIWISATA di Surabaya menjadi salah satu sektor unggulan pembangunan sehingga banyak bangunan cagar budaya yang direvitalisasi oleh pemerintah Kota Surabaya. [8]. Kunjungan wisatawan meningkat pesat pada 5 tahun terakhir, tercatat pada 2011 wisatawan nusantara dan mancanegara yang masuk berjumlah 9 juta kemudian pada tahun 2016 lebih dari 20 juta kunjungan [9]. Pertumbuhan tersebut karena adanya daya tarik potensi wisata dan keunikan budaya dan sejarah Surabaya sehingga dapat menarik wisatawan domestik dan internasional [1]

Pengembangan wisata budaya dan sejarah tersebut penting karena Surabaya tidak memiliki daya tarik alam, namun memiliki keunikan sejarah dan budaya yang potensial apabila dikembangkan. Surabaya sendiri berdiri sejak tahun 1293 menjadi salah satu kota tua di Indonesia yang peradabannya masuk melalui sungai Kalimas sehingga memiliki pelabuhan yang tua [10]. Keberadaan pelabuhan tua tersebut karena sungai Kalimas memiliki peran vital bagi masuknya perdagangan di Surabaya serta menjadi salah satu sarana transportasi air yang ramai sejak penguasaan VOC di Indonesia. Budaya Arab, Cina, dan Kolonial masuk melalui perdagangan secara tidak langsung menjadikan Surabaya sebagai kota tua yang memiliki karakter kota lama di sepanjang sungai Kalimas [10]. Budaya dan sejarah tersebut merupakan bagian dari kota lama yang tidak dapat dipisahkan [13]. Sehingga banyak ragam objek Daya Tarik Wisata (DTW) budaya dan sejarah di sekitar Sungai Kalimas. Beberapa diantaranya adalah Balai Kota Surabaya, Kawasan Tunjungan, Gedung Grahadi, Tugu Pahlawan, Monumen Jenderal Soedirman, Monumen Kapal Selam dan Balai Pemuda [9].

Potensi daya tarik budaya dan sejarah yang dimiliki Surabaya dilihat dengan adanya tren peningkatan kunjungan dari tahun 2013 hingga tahun 2016. Pada tahun 2015 meningkat sebesar 8\% dari tahun 2014 dan kemudian meningkat 18\% di tahun 2016. Dengan peningkatan tertinggi pada tahun 2014 sebesar 45,3 persen. Hal tersebut juga didukung dengan keberadaan Bandara Internasional Juanda sehingga Surabaya menjadi target destinasi wisata prioritas (Ratman, 2016). Review Rencana Induk Pengembangan Pariwisata Daerah (RIPPDA) Kota Surabaya tahun 2017 menunjukkan wisata budaya dan sejarah menarik 54,21\% kunjungan wisatawan mancanegara (wisman) dari seluruh DTW yang ada di Kota Surabaya.

Namun, objek daya tarik budaya dan sejarah di Surabaya sepi peminat, ditunjukkan dengan tidak meratanya kunjungan di setiap DTW. data Dinas Kebudayaan dan Pariwisata Kota Surabaya dalam Review RIPPDA Kota Surabaya (2017) [9], menunjukkan ketimpangan jumlah pengunjung pada DTW, seperti misalnya pada Monumen Kapal Selam dengan 323.875 orang sedangkan DTW Djoko Dolog hanya 952 orang pengunjung sepanjang tahun 2016. Ketimpangan terlihat lebih jelas pada kunjungan wisatawan mancanegara, pengunjung DTW House of Sampoerna sebesar 34.450 orang, sedangkan DTW Loka Jala Crana tidak memiliki pengunjung pada tahun 2016.

Terdapat penelitian sebelumnya menyatakan bahwa Surabaya sebagai salah satu kota besar di Indonesia, memiliki sejarah panjang terutama di Sekitar Sungai Kalimas. Namun Sungai Kalimas mengalami degradasi kondisi dan pembangunan disekitarnya tidak menyentuh sungai tersebut [2]. Selain itu tidak ada infrastruktur yang baik disekitarnya sehingga Sungai Kalimas kehilangan nilainilai yang seharusnya dapat menjadi daya tarik tersendiri. Penelitian lainnya di Sungai Kalimas yaitu mengenai potensi dalam rencana revitalisasi 3 titik di sepanjang sungai, disebutkan bahwa terdapat potensi pada titik Kawasan Pelabuhan Kalimas, Kawasan Jembatan Pethekan, dan Kawasan Jembatan Merah [3]. Potensi tersebut adalah adanya peninggalan bersejarah berupa bangunan cagar budaya yang memiliki nilai historis tinggi. Selain itu dekat dengan pusat kegiatan, seperti pariwisata dan perbelanjaan.

Berdasarkan pemaparan permasalahan dan kendala diatas, penelitian ini bertujuan untuk menentukan tema yang akan dikembangkan menjadi jalur wisata. Tema tersebut 
mempermudah penggolongan objek wisata dan dapat mempermudah wisatawan dalam menentukan tujuan wisata di Kota Surabaya.

\section{METODE PENELITIAN}

\section{A. Jenis dan Pendekatan Penelitian}

Pendekatan yang digunakan dalam penelitian ini adalah pendekatan studi positivistik. Pendekatan positivistik menekankan pemahaman bahwa keberadaan sesuatu merupakan besaran yang dapat diukur [4]. Dalam pendekatan tersebut semua objek penelitian harus dapat direduksi menjadi fakta empirik yang dapat diamati, dapat terukur, memiliki kriteria objektif dan mementingkan fenomena yang tampak. Jenis penelitian dalam penelitian ini adalah deskripti kuantitatif.

\section{B. Variabel Penelitian}

Sebelum melakukan proses identifikasi tema wisata budaya dan sejarah di Kota Surabaya, terlebih dahulu menentukan variabel yang berasal dari kajian pustaka. Variabel yang didapatkan untuk mengidentifikasi tema wisata budaya dan sejarah di Surabaya yaitu dari daya tarik budaya, sejarah, dan keberagaman atraksi setiap DTW yang ada.

Tabel 1.

Indikator dan Variabel dalam Penelitian

\begin{tabular}{ll}
\hline \hline Indikator & Variabel \\
\hline Tangible & Keberadaan bangunan bersejarah. \\
& Kesamaan atraksi \\
Intangibl & Budaya tradisional (kesenian, sejarah, drama dan \\
$e$ & teater) \\
& Keunikan sejarah \\
\hline
\end{tabular}

\section{Metode Pengumpulan Data}

Metode pengumpulan data dibagi menjadi primer dan sekunder. Data primer didapatkan dari in-depth interview dengan stakeholder kunci, kemudian data sekunder didapatkan dari survei literatur dan survei instansional. Pengumpulan data sekunder digunakan untuk mengeksplorasi dan validasi hasil observasi pada survei primer melalui data sekunder yang dimiliki oleh Bappeko Kota Surabaya, Dinas Kebudayaan dan Pariwisata. Dokumen tersebut antara lain Rencana Induk Pengembangan Pariwisata Daerah (RIPPDA) Kota Surabaya, RPJMD Surabaya, dan RTRW Kota Surabaya.

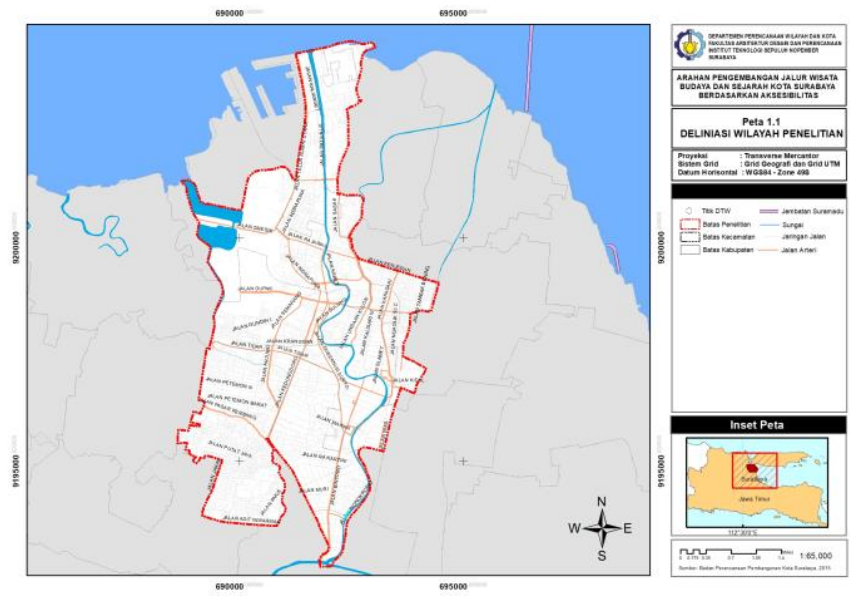

Gambar 1. Wilayah Amatan Penelitian, yaitu di Sepanjang Sungai Kalimas mencakup wilayah administrasi Surabaya Utara dan Pusat.

Metode purposive sampling digunakan untuk mencari responden sesuai dengan tujuan dan masalah penelitian. Responden yang dipilih harus sesuai dengan kepentingan dan kebutuhan, yaitu mengidentifikasi tema wisata budaya dan sejarah di Kota Surabaya. Purposive sampling adalah teknik penentuan sampel dengan pertimbangan khusus [5]. Kemudian menggunakan analisis stakeholder untuk menentukan responden kunci.

\section{Metode Analisis Data}

Penelitian kualitatif [4] ini menggunakan metode analisis deskriptif sesuai variabel yang telah dirumuskan sebelumnya. Desktiptif merupakan metode analisis untuk menjelaskan secara efektif dan efisien sehingga informasi penting dapat tertangkap sesuai dengan topik yang diteliti [11]. Deskripsi pada kutipan diberikan dari wawancara sebagai proses verifikasi setiap tema jalur yang dihasilkan.

Berdasarkan hasil stakeholder analisis, diketahui bahwa terdapat 5 responden yang memiliki pengaruh dan kepentingan dalam arahan pengembangan jalur wisata budaya dan sejarah di Kota Surabaya: Badan Perencanaan Kota, Dinas Kebudayaan dan Pariwisata, Agen Travel, pengelola DTW House of Sampoerna, dan Prof. Johan Silas sebagai akademisi serta anggota cagar budaya Surabaya.

\section{HASIL DAN PEMBAHASAN}

Undang-undang No. 10 tahun 2009 mendefinisikan wisata sebagai kegiatan seseorang melakukan perjalanan dengan mengunjungi tempat tertentu untuk tujuan rekreasi, pengembangan pribadi, atau mempelajari keunikan daya tarik wisata yang dikunjungi dalam waktu singkat. Wisata perkotaan diartikan adanya perjalanan yang dilakukan oleh wisatawan ke kota atau tempat dengan populasi tinggi dengan durasi pendek, yaitu dua hingga tiga hari [5]. UNWTO juga mengatakan kota adalah pusat budaya, sosial, politik dan perkembangan budaya yang modern sehingga memiliki daya tarik tersendiri. Wisatawan tertarik mengunjungi dan berwisata ke kota karena banyaknya daya tarik yang disediakan dan dapat dipenuhi dalamnya [6].

Wisata budaya merupakan jenis perjalanan pariwisata yang didorong oleh keberadaan aspek tempat, tradisi, kesenian, upacara, dan mendapatkan informasi baru dari suatu bangsa atau suku bangsa dengan masyarakat, yang merefleksikan keanekaragaman (diversity) dan identitas (character) dari suatu tempat tertentu [15] [7]. Wisata dengan sumber daya budaya menurut Gunn (2002), dibagi oleh Pitana dan Diarta (2009) menjadi lima jenis, yaitu budaya yang memiliki daya tarik bangunan bersejarah, museum, situs, monument, galeri seni, situs budaya kuno, dan lainnya. Kedua, seni dan patung kontemporer, arsitektur, tekstil, pusat design, pusat kerajian, dan lainnya [12]. Ketiga, festival, teater jalanan, seni pertunjukan, drama, dan even khusus lainnya. Keempat, peninggalan keagamaan seperti pura, gereja, candi, dan situs. Dapat disimpulkan bahwa wisata budaya adalah suatu perjalanan yang dilakukan berdasarkan motivasi budaya dari suatu tempat tertentu dengan daya tarik objek berupa gedung bersejarah, arsitektur, kesenian, peninggalan keagamaan serta kebiasaan masyarakat setempat.

Kemudian yang dimaksud wisata sejarah merupakan perjalanan mengetahui jejak dari generasi ke generasi 
berupa tangible dan intangible yang peninggalannya dapat digunakan sebagai media belajar dari kehidupan masa lalu [8]. Keberadaan dan tampilan bangunan merupakan objek utama yang mendasari daya tarik berbasis sejarah karena keunikan bangunan dan bentuk fisiknya menjadi identifikasi yang sekaligus membedakan dengan daerah tujuan wisata lainnya [14]. Astuti dan Noor (2016) juga mengatakan bahwa atraksi tangible dapat berupa bangunan heritage, istana, museum, kota bersejarah, monumem, areal arkeologi, gereja, dan masjid, sedangkan intangible dapat berupa kondisi sosial budaya masyarakat masa lalu maupun saat ini [5].

Lebih lanjut indikator yang mempengaruhi wisatawan untuk berkunjung ke objek wisata sejarah adalah indikator keunikan sejarah. Dapat disimpulkan bahwa karakteristik wisata sejarah adalah keberadaan fisik bangunan (tangible) dan identifikasi sejarah yang melatarbelakanginya (intangible) seperti adanya sosial budaya masyarakat, dan keunikan. Berdasarkan kajian literatur diatas didapatkan variabel sebagai berikut:

\section{A. Identifikasi Jenis Tema Wisata Budaya dan Sejarah Kota Surabaya}

Atraksi yang ditawarkan oleh DTW berbentuk pengenalan budaya dan sejarah Kota Surabaya, seperti bangunan tua, benda bersejarah, tradisi dan budaya lokal, festival budaya dan atraksi lainnya. Berdasarkan hasil komparasi teori, kebijakan, dan penelitian terkait, kriteria untuk variabel keberagaman atraksi DTW budaya dan sejarah yang didapatkan dari theoretical descriptive analysis adalah DTW dengan kesamaan paket/promosi wisata dan DTW dengan satu tema atraksi pendukung.

DTW dengan atraksi pendukung dikomparasi dengan kesamaan paket wisata. Atraksi pendukung DTW dilihat dari hubungan tema sejarah atau keterkaitan sejarah objek tersebut satu dengan lainnya. DTW yang tergabung dalam satu tema diperkuat dengan hasil wawancara dengan stakeholder. Sedangkan kesamaan paket tersebut didapat dari beberapa agen travel yang memiliki tour Surabaya, jalur dari House of Sampoerna, dan jalur wisata yang dimiliki pemkot Surabaya.

Dari hasil wawancara didapatkan keterangan penguat untuk pembentukan tema wisata budaya dan sejarah di Surabaya yang lebih spesifik. Terdapat 5 hubungan DTW yang memiliki keterkaitan tema budaya maupun sejarah yang sama dengan DTW disekitarnya. Kesamaan tema tersebut seperti kesamaan kawasan maritim, kawasan sejarah perjuangan Surabaya, dan gedung bersejarah zaman kolonial serta kawasan budaya. Sedangkan dari kesamaan paket atau promosi wisata terdapat 5 kelompok hubungan yang diambil dari paket milik agen travel Arby Tour and Travel Sidoarjo, Setia Abadi Tour Surabaya, dan Bromo Tour. Selain itu juga mengambil informasi kesamaan promosi dari jalur bus wisata yang dimiliki oleh House of Sampoerna dan Pemerintah Kota Surabaya dengan fasilitas Bus Heritage Tracks.

Kesamaan atraksi yang ditawarkan oleh DTW berbentuk pengenalan budaya dan sejarah Kota Surabaya, seperti bangunan tua, benda bersejarah, tradisi dan budaya lokal, festival budaya dan atraksi lainnya.

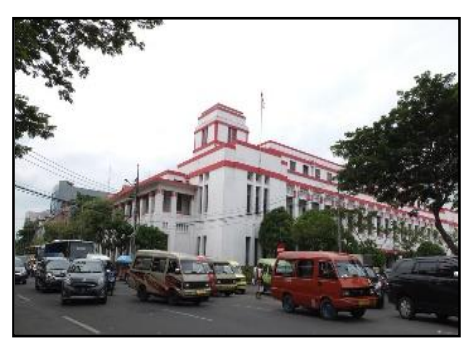

(a) (b)

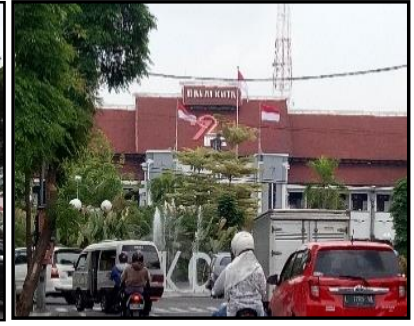

Gambar 2. Beberapa Daya Tarik Wisata Sejarah di Kota Surabaya, Balai Kota (a) dan Gedung Internatio (b)

DTW dengan atraksi pendukung dikomparasi dengan kesamaan paket wisata. Atraksi pendukung DTW dilihat dari hubungan tema sejarah atau keterkaitan sejarah objek tersebut satu dengan lainnya. DTW yang tergabung dalam satu tema diperkuat dengan hasil wawancara dengan stakeholder. Sedangkan kesamaan paket tersebut didapat dari beberapa agen travel yang memiliki tour Surabaya, jalur dari House of Sampoerna, dan jalur wisata yang dimiliki pemkot Surabaya.

\section{B. Identifikasi Kelompok Tema Sejarah}

Tema objek daya tarik wisata di Surabaya tersebut adalah sebagai berikut:

1. Tema maritim

Tema maritim merupakan tema yang baru muncul pada saat wawancara karena dalam data sekunder tidak terdapat tema maritim dalam promosi atau paket wisata yang ditawarkan oleh agen travel di Surabaya maupun di daerah lain. Namun Prof. Johan Silas mengatakan: "kalau utara merupakan satu tema tentang kelautan objeknya, dan itu menarik karena masuknya banyak budaya ke Surabaya dari sana."

Selain itu dilatarbelakangi bahwa Surabaya merupakan salah satu kota dengan pesisir di Jawa Timur. Sehingga perkembangan kota ini tidak lepas dari pelabuhan sebagai letak masuknya peradaban. Ditambahkan oleh Prof. Silas "ada wisata maritim yang merupakan satu tema tentang kelautan objeknya, dan itu menarik karena masuknya banyak budaya ke Surabaya dari sana." Ditambahkan Bu Rini selaku manajemen Bus Surabaya Heritage Track (SHT) di House of Sampoerna, mengatakan:”.... (Surabaya) banyak sejarah yang membentuk identitas salah satunya dikenal sebagai kota pelabuhan. Port city juga pelabuhan di Surabaya sebagai perdagangan, itu yang melatarbelakangi kita membuat jalur tentang sejarah".

Hasil wawancara tersebut sesuai dengan hasil observasi di lapangan bahwa di Utara Surabaya terdapat pesisir dengan kesamaan atraksi disekitarnya. Selain itu terdapat pelabuhan perak sebagai sarana tranportasi laut, monument Jalesveva Jayamahe di kawasan TNI, Jematan Pethekan, dan berbagai wisata lain di sebelah barat Sungai Kalimas di utara.

2. Tema gedung bersejarah:

Surabaya terkenal dengan sejarah kolonialisme ditunjukkan dengan adanya banyak bangunan tua di pusat kota Surabaya. Kemudian tema ini banyak masuk dalam paket wisata jalur SHT yang dibuat oleh House of Sampoerna.

Ibu Tri (Bappeko) mengatakan "Di RIPPDA terbaru, ada gabungan antara kampung, heritage, bangunan cagar budaya, museum, dan lingkungan. Untuk cagar budaya dan museum di Surabaya utara, paketnya digabungkan dengan jarak terdekat. Misal Gedung Internatio, PTPN, bisa dijadikan satu paket karena bangunan kawasan bangunan 
bersejarah...". Pernyataan tersebut menunjukkan banyaknya daya tarik bangunan kolonial yang terdapat di Surabaya.

Prof. Silas menambahkan “...kawasan ini bagus karena merupakan segitiga sejarah Surabaya, dari Jalan VeteranJalan Rajawali-Jalan Kepanjen. Bangunannya sejarah kolonial, bisa melihat suasana kehidupan dahulu."

Hasil wawancara tersebut sesuai dengan amatan observasi bahwa di Jalan Rajawali, Jalan Kepanjen, dan Jalan Veteran hingga Jalan Tunjungan, banyak terdapat bangunan dengan gaya kolonial. Bangunan tersebut seperti Gedung Internatio, Gedung Bank Niaga, Gedung PTPN XXII, Museum Kesehatan, Gedung Pertamina, Kantor Gubernur, Gereja Kepanjen, dan Tugu Pahlawan. Maka terbentuklah tema gedung bersejarah di Kota Surabaya yang menarik apabila dikemas menjadi wisata sejarah.

Kesamaan atraksi yang dimiliki objek tersebut adalah adanya gaya bangunan arsitektur kolonial yang unik dan beberapa memiliki museum sejarah. Selain itu kawasan tersebut telah banyak direvitalisasi, baik gedung, trotoar, dan prasarana transportasi lainnya.

3. Tema Sejarah Perjuangan Kemerdekaan RI di Surabaya:

Tema ini banyak digunakan oleh pemkot Kota Surabaya untuk mengenalkan perjuangan kemerdekaan. Selain itu dilatarbelakagi bahwa Surabaya disebut sebagai Kota Pahlawan. Seperti yang disampaikan oleh Bu Rini selaku manajemen HoS, yang menyampaikan: "Kekuatan di Surabaya lebih pada sejarahnya dibanding Bali, Lombok atau Batu yang punya kekuatan alam. Surabaya memiliki aspek historical kuat. Mudahnya Surabaya dikenal sebagai kota Pahlawan. Itu yang membuat Surabaya mempunyai identitas kota yang kuat, selain itu kota ini tua dengan umur 728 tahun."

Bapak Robby sebagai pelaku wisata yang menyediakan paket tur mengatakan, "...daya tarik ke wisatawan, mereka ingin tahu sejarah apa yang mengandung. Surabaya terkenal sebagai Kota Pahlawan. Jadi kami membuat paket wisata ke Surabaya. Rata-rata yang minat orang luar Jatim. Tати Malaysia juga banyak yang mau jalan-jalan di Surabaya,"

Dari hasil observasi, terutama di Kalimas bagian barat juga didapatkan kesamaan atraksi yang menunjukkan adanya peringatan berupa monument untuk perjuangan kemerdekaan di Surabaya. Seperti monumen Bambu Runcing, Monumen Kapal Selam, Patung Jendral Soedirman, Balai Pemuda, kemudia Gedung Grahadi, Patung Joko Dolog, Patung SuroBoyo, Monumen Gubernur Suryo, dan Gedung RRI. Sehingga dapat disimpulkan terdapat tema sejarah Perjuangan Kemerdekaan Republik Indonesia di Surabaya.

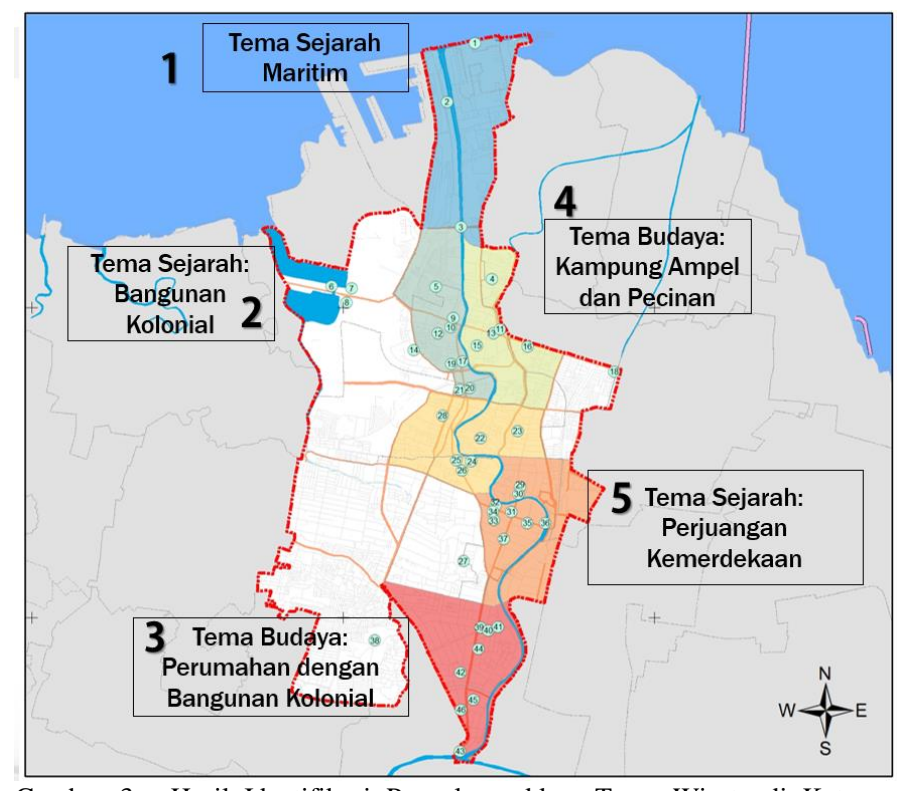

Gambar 3. Hasil Identifikasi Pengelompokkan Tema Wisata di Kota Surabaya.

\section{Identifikasi Kelompok Tema Budaya}

\section{Tema Budaya: Permukiman Kampung}

Budaya di Surabaya beragam karena mengingat banyaknya orang yang masuk melalui pintu perdagangan di pelabuhan. Budaya yang masuk tersebut membentuk kawasan, seperti Kampung Ampel dan Pecinan di Kya-kya. Kawasan Ampel, Klenteng Hok Tiek Han, Kya-kya dan Kawasan Jembatan Merah, memiliki banyak daya tarik budaya karena memiliki kawasan kampung dengan berbeda etnis. Terdapat kesamaan jenis atraksi yang ditawarkan, seperti kuliner, berbelanja, dan mengunjungi permukiman kampung dengan berbagai macam latar belakang budaya. Berbagai budaya tersebut seperti, dominasi kehidupan budaya Arab untuk di Kampung Ampel dan dominasi kehidupan budaya Cina di Kampung Pecinan.

Tema ini muncul salah satunya berdasarkan paket wisata yang dibuat oleh beberapa agen perjalanan yang memiliki tema budaya ini dalam paket wisatanya, terutama dalam mengunjungi Kawasan Ampel. Dalam hal peradaban budaya yang masuk di Surabaya terdapat tema Kampung Ampel dan Kampung Pecinan di sekitar Kya-kya yang dimasukkan oleh salah satu agen perjalanan. Kemudian Prof. Silas menekankan, bahwa perkampungan budaya penting dalam sejarah masuknya perkembangan Kota Surabaya:

“...sebenarnya kalau bicara sejarah dan budaya-budaya Surabaya itu ada di kampung-kampungnya. Di sisi timur Sungai Kalimas, ada Kampung Arab, ya... kawasan Ampel. Kemudian ke selatan sedikt ada kawasan Pecinan. Kawasan ya, kalau Kya-kya sendiri sudah mati, dead. Jadi kalau ke kampung-kampungnya lebih menarik. Ada juga Kampung Keraton, disitu menandakan dulunya Surabaya punya Keraton, tidak Jawa Tengah saja..."

Dari hasil observasi juga didapatkan adanya budaya yang ditunjukkan dengan ornamen bangunan yang berbeda dari kawasan lain. Seperti adanya klenteng-klenteng di Pecinan dan banyak masjid di Kawasan Ampel. Tidak hanya dua budaya tersebut, namun kampung yang telah lama ada seperti Kampung Keraton dan Kampung Lawas Maspati. Sehingga terbentuklah Tema Budaya di Surabaya Utara, tepatnya di sisi Timur Sungai Kalimas. 


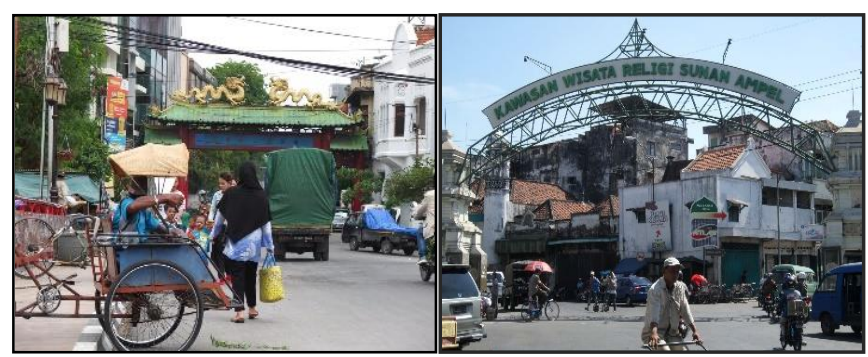

(a)

(b)

Gambar 4. Beberapa Daya Tarik Wisata Budaya di Kota Surabaya, Kawasan Pecinan (a) dan Kawasan Ampel (b)

2. Tema Budaya di Perumahan Kolonial Belanda

Observasi di lapangan di daerah Darmo, yaitu diselatan

Sungai Kalimas terdapat atraksi berupa Gedung Saint Louis,

Gereja Kathedral, Monumen Perjuangan Polri, Rumah Sakit Darmo, Gedung Santa Maria, Makam Ki Ajeng Bungkul, Perpustakaan Bank BI, dan Monumen Wira Surya. Memang terlihat bahwa bangunan tersebut berarsitektur gaya kolonial. Atraksi yang ditawarkan seperti berupa taman, gedung kolonial, dan juga perumahan yang berbeda dengan kawasan lainnya. Prof. Silas menyatakan bahwa di ujung Sungai Kalimas juga banyak terdapat bangunan kolonial. Tepatnya di Jalan Darmo, "Selatan... Darmo banyak perumahan kolonial, Kathedral, juga perpustakaan BI. Banyak yang sudah di-revitalisasi dan menarik itu."

Budaya yang masuk tidak hanya dari Timur dan Asia, namun juga ada budaya yang terbentuk selama masa penjajahan di Kota Surabaya. Sehingga kawasan ini terkait dengan sejarah bangunan kolonial sebelumnya. Sehingga dari kesamaan atraksi yang ditawarkan berupa banyaknya rumah dan gedung bergaya kolonial, membentuk tema "perumahan bangunan kolonial".

\section{KESIMPULAN}

Penelitian ini bertujuan merumuskan tema wisata sejarah dan budaya di Kota Surabaya berdasarkan pendapat stakeholder kunci. Analisis identifikasi didapatkan 5 tema wisata budaya dan sejarah, yaitu: tema 1 terdiri dari DTW Monumen Jalesveva Jayamahe, Pelabuhan Tradisional Kalimas, dan Jembatan Pethekan merupakan tema maritim.

Tema 2 (tema sejarah bangunan kolonial) terdiri dari DTW House of Sampoerna, Gedung Internatio, Gedung Bank Niaga, Gedung PTPN XXII, Museum Kesehatan, Gedung Pertamina, Kantor Gubernur, Gereja Kepanjen, dan Tugu Pahlawan.

Tema 3, yaitu tema sejarah perumahan kolonial terdiri dari DTW Gedung Saint Louis, Gereja Kathedral, Monumen Perjuangan Polri, Rumah Sakit Darmo, Gedung Santa Maria, Makam Ki Ajeng Bungkul, Perpustakaan Bank BI, dan Monumen Wira Surya.

Tema 4 yang merupakan tema kampung budaya Surabaya, terdiri dari DTW Kawasan Ampel, Klenteng Hok Tiek Han, Kya-kya dan Kawasan Jembatan Merah.

Dan terakhir tema 5 (perjuangan kemerdekaan) adalah DTW Siola, Kawasan Tunjungan, Makam Peneleh, dan Masjid Cheng Ho, dan Gedung Nasional Indonesia, Balai Kota, Monumen Jendral Sudirman, dan Balai Pemuda, kemudian DTW Gedung Grahadi, Patung Joko Dolog, Monumen Gubernur Suryo, Gedung RRI, Monumen Kapal Selam, dan Monumen Bambu Runcing. dengan DTW Dari hasil diharapkan dapat dikembangkan dalam bentuk jalur wisata tematik sehingga mempermudah wisatawan dalam meyesuaikan minat dan tujuan kunjungan.

\section{UCAPAN TERIMA KASIH}

Penulis mengucapkan terima kasih kepada Badan Perencanaan Kota, Dinas Kebudayaan dan Pariwisata, Agen Travel, pengelola DTW House of Sampoerna.

\section{DAFTAR PUSTAKA}

[1] R. B. Lestari and R. Aprilia, "Membangun Nation Branding Dalam Upaya Meningkatkan Daya Saing Sektor Pariwisata Indonesia," PESAT (Psikologi, Ekon. Sastra, Arsit. Tek. Sipil), vol. 5, pp. 8-9, 2013.

[2] H. Idajati, "Cultural And Tourism Planning As Tool For City Revitalization The Case Study Of Kalimas River, SurabayaIndonesia," vol. 135, pp. 136-141, 2014.

[3] I. Arbani and H. Idajati, "Identifikasi Potensi dan Masalah dalam Revitalisasi Kawasan Sungai Kalimas di Surabaya Utara,” J. Tek. ITS, vol. 6, no. 2, pp. 526-528, 2017.

[4] M. Mulyadi, "Penelitian Kuantitatif dan Kualitatif serta Pemikiran Dasar Menggabungkannya," J. Stud. Komun. dan Media, vol. 15, no. 1, pp. 127-138, 2011.

[5] M. T. Astuti and A. A. Noor, "Daya Tarik Morotai Sebagai Destinasi Wisata Sejarah dan Bahari," J. Kepariwisataan Indones., vol. 11, no. 1, pp. 25-46, 2016.

[6] S. M. Rasoolimanesh, C. M. Ringle, M. Jaafar, and T. Ramayah, "Urban vs. rural destinations: Residents??? perceptions, community participation and support for tourism development," Tour. Manag., vol. 60, pp. 147-158, 2017.

[7] J. Csapó, "The Role and Importance of Cultural Tourism in Modern Tourism Industry, Strategies for Tourism Industry.," Univ. Pecs, Inst. Geogr. Tech Hungary., 2012.

[8] UNWTO, "Affiliate Members Global Reports, Volume twelve Cultural Routes and Itineraries, UNWTO, Madrid.," World Tour. Organ., 2015.

[9] Review RIPPDA (Rencana Induk Pengembangan Pariwisata Daerah) Kota Surabaya. 2017.

[10] Bappeda Provinsi Jatim. 2013. Profil Kabupaten/Kota: Kota Surabaya. Diakses: $25 \quad$ Oktober $2017 \quad$ dari http://bappeda.jatimprov.go.id/bappeda/wp-content/uploads/ potensi-kab-kota-2013/kota-surabaya-2013.pdf.

[11] Gabor, Manuela. 2010. Descriptive Methods of Data Analysis for Marketing Data-- Theoritical and Practical Considerations. Universitu of Tg. Mures: Romania.

[12] Pitana dan Diarta. 2009. Pengantar Ilmu Pariwisata. Andi: Yogyakarta.

[13] Putra, R.D.W. 2016. Identifikasi Kelestarian Kawasan Kota Lama Melalui Proteksi Bangunan Cagar Budaya Oleh Pemerintah Kota Surabaya. Jurnal Pengembangan Kota Vol 4 (2).

[14] Adi, S.W. \& Saputro, E.P. 2017. Potensi Daya Tarik Wisata Sejarah Budaya. The 5 UAD, Yogyakarta TH Urecol Proceeding, (February), pp.475-481.

[15] Ismayanti. 2010. Pengantar Pariwisata. Grasindo: Jakarta. 